\title{
Mental Health Crisis Training for Non-mental Health Professionals
}

\begin{tabular}{|r|l|}
\hline Journal: & Journal of Mental Health Training, Education and Practice \\
\hline Manuscript ID & JMHTEP-11-2019-0062.R1 \\
\hline Manuscript Type: & Research Paper \\
\hline Keywords: & Crisis Support, Non-Mental Health Professionals, Training \\
\hline \multicolumn{2}{l}{} \\
\end{tabular}




\section{Mental Health Crisis Training for Non-mental Health Professionals}

\section{Purpose}

This study evaluates a training in Mental Health Crisis Support for Non-Mental Health Professionals who work in urgent care settings. The training consists of an e--learning module, a one-day face to face (F2F) interactive study day and simulation training.

\section{Design}

This mixedmulti-methods study collected data pre and post training and at three to six months post training. Validated questionnaires, rating scales and open-ended questions were used to measure self-efficacy in healthcare skills, attitudes towards mental illness, and knowledge and confidence in working in mental health. A subsample of participants was interviewed post training about how they had used the knowledge and skills learned.

\section{Findings}

706-Seven hundred and six staff completed the e-learning, 88 attended the F2F training and 203 attended simulation training. Overall satisfaction with the training was high, with F2F and simulation training preferred. Statistically significant improvements in self-efficacy for healthcare skills, positive attitudes towards mental illness, and mental health-related knowledge and confidence were found post training. Qualitative analyses of interview and survey data indicated that participants had translated learning to practice through improved attitudes and behavioural changes when working with patients experiencing a mental health crisis.

Value

This training improved mental health-related knowledge, confidence and self-efficacy and reduced mental health-related stigma in professionals who provide urgent care to people in mental health crisis. Participants reported changes to their practice following training; this is important as care has been inadequate for this group. Workforce planners and leaders should consider implementing this or similar training widely.

Key Words

Crisis Support, Non-Mental Health Professionals, Training

WORDS - 245

\section{Background}

People experiencing a mental health crisis come into contact with a range of professionals who are not mental health specialists. The Mental Health Crisis Care Concordat (2014) states "All (health and 
social care) staff should have the right skills and training to respond to mental health crises appropriately". However, a report by the Care Quality Commission (2015) noted that such professionals "appear to lack compassion and warmth in how to care for and speak to people who are having a crisis". Similarly, people with mental illness commonly report experiencing stigma and discrimination from healthcare staff (O'Reilly et al., 2010; Rong et al., 2011, Clifton et al., 2016). This may result from non-mental health professionals lacking the necessary skills and knowledge.

Mental health-related training may help, though the evidence for the effectiveness of such training is mixed. In a randomised controlled study of classroom-based mental health training for police officers (Scantlebury et al., 2017), reporting of mental health-related incidents improved, but there was no impact on the number of incidents reported. However, a review of educational interventions aimed at reducing mental health-related stigma found improvements in knowledge and behaviour (Thornicroft et al., 2016), with interventions which included social contact found to be most effective, at least in the short term (Mehta et al., 2015; Thornicroft et al., 2016; Mehta et al., 2015).

Simulation training, where clinical scenarios are recreated in safe environments, generally aims to improve quality of care by focusing not only on increasing participants"s knowledge, but on human skills essential for high quality care such as multi-disciplinary collaboration, communication and reflection (Thomson et al., 2013; Miller et al., 2012; Attoe et al., 2016; Billon et al., 2016; Thomson et al., 2013; Miller et al., 2012). Simulation training has been used extensively for medical education, but it is yet to flourish in mental health training (Attoe et al., 2016;). For a range of conditions, it has been found to lead to an increase in knowledge and confidence (Bremner et al., 2006; Zigman et al., 2013; Fernando et al., 2017; Piette et al., 2018; Zigman et al., 2013) and improved attitudes (Goldfarb and Gorrindo, 2005; Kowalskiet al., 2017; McNaughton et al., 2008; Thomson et al., 2013; Kowalski et al., 2017), and clinical behaviours (Lavelle et al., 2017).

This study aimed to evaluate the effectiveness of training in managing mental health crises for nonmental health professionals working in urgent care settings. Informed by the above research the training was developed to include social contact with people with mental health problems, a focus on stigmatising attitudes and behaviours and on skills development.

\section{Methods}

\section{Study design}

The study employed a multi-mixed-methods design to assess the learning of training participants, the reasons for this learning and impact on returning to the workplace. The methods were informed by Kirkpatrick's Four Levels of Evaluation model, with data collected for each level (see Table 1) 
(Kirkpatrick, 1959; Kirkpatrick, 1998). This model is a well-established and effective method for evaluating the effectiveness of training programmes in a variety of healthcare contexts (LavoieTremblay et al., 2012; Blumenthal et al., 2014; Fernandez et al., 2015; Dorri et al., 2016; Fernandez et al., 2015; Lavoie-Tremblayet al., 2012).

Ethical approval was granted by the University of West London College of Nursing, Midwifery and Healthcare Research Ethics Committee, and King's College London Psychiatry, Nursing and Midwifery Research Ethics Committee.

Table 1. Kirkpatrick's four Levels of Evaluation (Kirkpatrick, 1959; Kirkpatrick, 1998).

\begin{tabular}{|c|c|c|}
\hline Level of Evaluation & Evaluation Description & Evaluation Methods \\
\hline Reaction & $\begin{array}{l}\text { Participants' satisfaction with the } \\
\text { training }\end{array}$ & $\begin{array}{l}\text { Post-training questionnaires* } \\
\text { Post-training interviews }\end{array}$ \\
\hline Learning & $\begin{array}{l}\text { Changes in participants' } \\
\text { confidence, mental health- } \\
\text { related stigma, healthcare skills } \\
\text { Improved mental-health } \\
\text { knowledge }\end{array}$ & $\begin{array}{l}\text { Pre and post-training } \\
\text { questionnaires* } \\
\text { Post-training interviews }\end{array}$ \\
\hline Behaviour & $\begin{array}{l}\text { Application of learning to the } \\
\text { workplace }\end{array}$ & Post-training interviews \\
\hline Results & $\begin{array}{l}\text { Satisfaction with care received by } \\
\text { people experiencing a mental } \\
\text { health crisis or their carers or } \\
\text { relatives }\end{array}$ & $\begin{array}{l}\text { Post-training interviews (staff } \\
\text { views on impact on patients and } \\
\text { carers as a proxy measure of } \\
\text { patient/carer views) }\end{array}$ \\
\hline
\end{tabular}

- Please see measures section for details: Mental Illness Clinicians Attitudes (MICA-4)

(Gabbidon et al., 2013), Reported and Intended Behaviour Scale (RIBS) (Evans-Lacko et al., 2011), Human Factors Skills for Healthcare Instrument (HFSHI), Course specific questions scale, Course evaluation questionnaire.

\section{Participants}


Participants were recruited from ambulance and police services, general practice and A\&E departments across the Thames Valley region via adverts on Trust websites. Support was required from managers to attend, places were funded by Health Education England Thames Valley (HEETV).

\section{Training}

The training was designed by a team of academics and mental health practitioners from three Higher Education Institutions in Thames Valley, Maudsley Simulation and MIND Buckinghamshire. The aim was to improve staff knowledge, confidence, attitudes and skills to support someone experiencing a mental health crisis.

Funding for a two-day course plus additional simulation training for those with a particular interest e.g. service mental health leads, was provided. To minimise the requirement for backfill, day one consisted of $\mathrm{e} E$-learning produced by the HEE e-Learning for Healthcare (eLfH) team which meant it was easily accessible via most NHS sites. Day two was a face to face (F2F) experiential study day where, following an overview of the e-lt-earning (to review knowledge and in case some participants had not completed it), staff and participants developed and role-played meaningful scenarios which were followed by a reflective debrief whereby participants reflected on what happened in the role plays including what was done well and what could have been done better. A cost effective and easy to roll out method of including S-Social contact was included in the training was-through the use of videos of real life stories which were produced by MIND Buckinghamshire; this was a costeffective approach which would be easy for others wishing to deliver this training to implement. The simulation training courses were designed and delivered by clinical and educational experts in mental health, with the help of technicians and actors to run simulated scenarios, and service user input to the training development (for example, further detail provided in Fisher, Vishwas, Cross \& Attoe, 2019).

\section{Procedure}

Participants were administered questionnaires (as detailed below) prior to and immediately post the F2F day and simulation training in order to assess changes in their knowledge, confidence, attitudes and skills and to assess their satisfaction with the training. All participants provided informed consent, were informed of their right to withdraw and given information on the study.

Participants were asked to indicate their consent to be approached for interview three to six months after their training session. Interviews were conducted by a member of the research team who was 
blinded to the training programme, at a convenient time and location for participants, and were audio-recorded and transcribed verbatim for analysis.

\section{Measures}

A range of measures was used to assess changes in attitudes (MICA-4, Gabbidon et al., 2013, and RIBS, Evans-Lacko et al., 2011), knowledge and confidence (Likert scales) and skills (HFSHI, Reedy et al., 2017) as well as satisfaction with the training (course evaluation questionnaire).

Mental Illness Clinicians Attitudes (MICA-4) (Gabbidon et al., 2013): This validated scale comprises 16 items, rated on a six6-point Likert scale. A low total score represents less stigmatizing attitudes towards mental illness and psychiatry.

Reported and Intended Behaviour Scale (RIBS) (Evans-Lacko et al., 2011): Self-report past, current and intended behavioural discrimination towards people with mental health problems is assessed using a validated 8-item self-report questionnaire. A high score indicates high intended social proximity (i.e. how close an individual is willing to get to someone with a mental health problem).

Human Factors Skills for Healthcare Instrument (HFSHI): this is a 12-item self-report questionnaire, rated by participants on a 10-point Likert scale from 1 (definitely cannot do) to 10 (definitely can do) to measure self-efficacy. Clinicians were given the original version of the questionnaire, while nonclinical participants were given an adjusted version, both of which have been validated (Reedy et al., 2017). A higher score represents higher self-efficacy.

Course specific questions scale: This 7-item self-report questionnaire was developed for this study and comprises statements relating to confidence and knowledge of mental health crisis care, rated on a 10-point Likert scale from 1 (totally disagree) to 10 (totally agree). Higher scores indicate higher self-reported confidence and knowledge.

Course evaluation questionnaire: This structured survey, developed for this study. included a range of questions evaluating the simulation course, both open ended questions with free-test responses to collect feedback on their experience of the training, and statements to rate on a 5-point Likert scale.

\section{Data Analysis}


Paired samples t-tests using SPSS 21 (IBM Corp 2012), explored change in participants' human factors skills, knowledge, confidence and attitude scores pre and post training, with effect size calculated using Cohen's D. Means and standard deviations were calculated from satisfaction ratings from the post-training evaluation survey.

Free text responses to post training evaluation questions and interview data were assessed separately using thematic analysis to examine participants' perceptions of the impact of the simulation training. Free text responses and verbatim transcripts of the interviews were coded independently, then agreed, by two researchers (free text responses: CA and PM; interviews: EB and RM). An initial list of codes was developed through repeated reading of the transcripts. The list of codes was then reviewed by the two researchers who then identified and agreed themes. Any codes that were unclear were re-visited in the transcripts to clarify their meaning and ensure proper theme assignmentData were transcribed before two researchers completed free coding and subsequently decided on final codes, organising them into themes for interpretation (Green and Thorogood, 2004). Themes were agreed by the team.

\section{Findings}

\section{Demographic Data}

The e--learning, which as mandatory for attending the F2F and simulation training, was available for one year (September 2017 to August 2018), 706 staff from the HEETV region completed it. Thirteen F2F days and 25 simulation training days were held. Staff had a range of backgrounds including nursing, allied health, social care and administrative and professional support staff, with demographics summarised in Table 2.

Table 2: Training participant characteristics

\begin{tabular}{|l|l|l|l|}
\hline \multicolumn{2}{|l|}{} & F2F & $\begin{array}{l}\text { Simulation } \\
\text { Training }\end{array}$ \\
\hline Total trained $(\mathrm{n})$ & 88 & 203 \\
\hline Male $(\mathrm{n})$ & 57 & 122 \\
\hline Female $(\mathrm{n})$ & 22 & 81 \\
\hline Age range & 22 to 60 years & 21 to 65 years \\
\hline Profession/role $(\mathrm{n})$ & Nurse & 32 & 61 \\
\hline & Doctor & 3 & 24 \\
\hline
\end{tabular}




\begin{tabular}{|c|c|c|c|}
\hline & Other healthcare & 5 & 29 \\
\hline 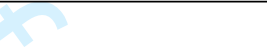 & Police & 37 & 43 \\
\hline & Ambulance & 0 & 46 \\
\hline \multicolumn{2}{|c|}{ Time since qualifying } & 1 to 33 years & 1 to 35 years \\
\hline \multirow[t]{6}{*}{$\begin{array}{l}\text { Personal } \\
\text { experience of } \\
\text { mental health } \\
\text { problems (\%) } \\
\text { [standardised } \\
\text { questions from - } \\
\text { RIBS] }\end{array}$} & $\begin{array}{l}\text { Lived with someone } \\
\text { with a mental } \\
\text { health problem }\end{array}$ & $42.7 \%$ & $47.2 \%$ \\
\hline & $\begin{array}{l}\text { Worked with } \\
\text { someone with a } \\
\text { mental health } \\
\text { problem }\end{array}$ & $73.2 \%$ & $84.1 \%$ \\
\hline & $\begin{array}{l}\text { Had neighbour with } \\
\text { a mental health } \\
\text { problem }\end{array}$ & $20.7 \%$ & $18.8 \%$ \\
\hline & $\begin{array}{l}\text { Close friend with a } \\
\text { mental health } \\
\text { problem }\end{array}$ & $68.3 \%$ & 71.9 \\
\hline & $\begin{array}{l}\text { Personal Mental } \\
\text { Health problem - } \\
\text { yes }\end{array}$ & $28 \%$ & $24.3 \%$ \\
\hline & $\begin{array}{l}\text { Personal Mental } \\
\text { Health problem - } \\
\text { prefer not to say }\end{array}$ & $6.1 \%$ & $4.5 \%$ \\
\hline
\end{tabular}

Fifty-nine participants (29\%) had-completed both F2F and simulation training.

A total of eight participants agreed to be interviewed after two email reminders. Five were police officers (with varying roles), one was a nurse, another a GP trainee and the final a receptionist/healthcare assistant in an A\&E department. All had attended the F2F training and five had attended the simulation training. Interviews lasted an average of 21 minutes. 


\section{Quantitative Findings \\ Mental Health Stigma}

F2F participants:

Mmental health-related stigma was reduced post intervention, though changes were not statistically significant: attitudes improved [MICA-4 mean (SD) pre $=35.4$ (6.8); post $=34.0$ (7.9) $p=0.051, n=$ 70)]; intended behaviour improved [RIBS mean (SD) pre = 16.9 (2.2); post $=17.3(2.3) p=0.047, n=$ 74]. Improvements were also seen between baseline and three months follow up, though only a few participants returned the follow up measures (MICA-4 $n=10$, RIBS $n=11$ ) so these findings should be interpreted with caution: attitudes improved [MICA-4 $n=10$, mean (SD) pre $=35.4(5.6)$; post = $32.7(4.6) p=0.01$; intended behaviour improved [RIBS $n=11$, mean (SD) pre = $15.3(2.1)$; post $=$ $15.6(3.6) p=0.79]$.

\section{Simulation training participants:}

Tthere was a statistically significant decrease in RIBS scores, from pre course $(M=12.53, S D=4.52)$ to post course $(M=11.54, S D=5.13), t(159)=-2.29, p=0.023$, (with a small effect size -0.18 ) this showed that after simulation training there was a decrease in behavioural discrimination among people with mental health problems. A similar pattern was found on scores of the MICA-4, with post training scores $(M=56.10, S D=16.56)$ dropping compared to pre training scores $(M=58.32, S D=$ $9.49)$, however this was not statistically significant, $t(162)=-1.69, p=0.094)$.

\section{Healthcare Skills}

\section{F2F participants:}

Oeverall, participants' scores on the HSFH scale were higher post training, this difference was statistically significant: [HFSH mean (SD) pre $=147.0$ (16.6); post $=152.5(16.3) p=<0.0001, n=70$. This improvement was maintained three months post training in the 11 participants for whom data were available, though the change from baseline was not statistically significant: mean (SD) pre = $139.2(20.4) ;$ post $=147.7(17.4) p=0.07$.

\section{Simulation training participants:}

Tthere was a statistically significant increase in HSFH scores pre course $(M=135.66, S D=27.97)$ to post course $(M=148.36, S D=22.39), t(151)=5.75, p<.001$. Effects sizes were medium, 0.47 . 


\section{Knowledge and Confidence}

\section{F2F participants:}

CEompared with before training, participants reported statistically significant improvements post training in their knowledge and confidence to manage someone experiencing a mental health crisis $_{L} \div$ [sum of Likert scales mean (SD) pre = 26.03 (7.77); post $19.29(5.45), \mathrm{p}<0.0001, \mathrm{n}=68$ ]. This improvement was maintained at 3 months in the 10 participants for whom data are available $\div$ - $[$ sum of Likert scales mean (SD) pre $=28.50$ (6.69); post 21.20 (5.65), $p<0.0001, n=10]$.

\section{Simulation training participants:}

Ssignificant improvement in participants' ratings of their ability to manage patients experiencing a mental health crisis was also found post training compared with pre training: CSQ scores pre course $[f M=46.06, S D=14.79]+$ to post course $[f M=53.16, S D=17.12 \nmid, t(163)=5.08, p<0.001]$. Effects sizes were medium, 0.40 .

\section{Qualitative Survey Findings}

Thematic analysis of participants' responses to the evaluation survey post F2F and simulation training identified three broad categories: increased engagement with people experiencing a mental health crisis; improved empathy and communication with people experiencing a mental health crisis; and plans to liaise and collaborate more with other professionals. Supporting quotes are identified by participant number.

Increased engagement

There was census that, following the training, participants planned to engage more with people experiencing a mental health crisis: "be more interactive with mental health patients instead of waiting GP/CAMHS" (P53) and "keep offering a friendly face and support despite not being able to fix" (P66). They referred to anticipating being more confident in their interactions: "be less anxious about talking to anyone with mental health issues" (P63), being prepared to spend more time with such people, reflecting on how their own actions may impact on people in crisis and moderating their behaviour accordingly: "self-reflecting how I am acting/ feeling is being perceived" (P53) and "Be more aware of how my actions may impact the patient" (P76) and acting on patient need "move 
patient no matter how busy, try to move patient away from crowded room, try to engage first with the patient" (P85). Reports of having an increased understanding of the reasons underlying challenging behaviour may be related to this: "appreciate how up bringing can directly affect mental health and behaviour" (P54).

Empathy and Communication

The majority of participants commented that they felt that, having attended the course, they would be better able to communicate with people experiencing a mental health crisis. Some listed specific skills they had learned and planned to use such as: 'validation', using silence, admitting when they donotn't have the answers, explaining procedures, using both direct and open questions more often, observing body language, listening actively and discussing suicide risk openly as part of a risk assessment. Many comments appeared to reflect an intention to display more empathy: "be able to understand in more detail what a person is suffering from" ( $p 13)$, be less judgemental or stigmatising: "thinking of a mental health illness as the same as other illness" (P47), and to attempt to ensure that interactions with clients in crisis were positive: "ensure each interaction to be positive in some ways." (P64). A few participants responded that they planned to look after their own and their colleagues' mental health better: "look closer at stress at work" (P51).

Several participants reported that, as a result of the training, they had learned how to communicate better with someone in crisis "how to speak and engage with someone in crisis" (P13). Related to this were reports of increased empathy and ability to 'mentalise' (the ability to see ourselves as others see us, and others as they see themselves) "understanding what feelings that person has and your own feelings" (P1) and "learning about how to validate someone's feelings rather than be dismissive (accidentally or otherwise)" (P52). A new ability to assess risk, including suicide risk and to be able to identify that someone was in crisis was reported. One participant reported having gained skills in their own stress management.

\section{Liaison and collaboration}

Participants were explicit that undertaking the training with others from a range of professions was highly valued: "Listening to experience from those not in policing" (P56) and "hearing different perspective from different professionals and work environments" (P65). They felt that this increased their understanding of others' roles and how they could better work together. Consequently, participants' responses evidence much greater preparedness to liaise with other professionals and 
services, with some participants commenting that notifying emergency services would no longer be there first response: "call crisis team before ambulance" (P25). This appeared to be related to comments around understanding the role and availability of other services and that other services to their own also face challenges which they should consider: "have more consideration to the impact that my decision may have upon partner agencies" (P4O). Several participants responded that they planned sharing their learning with their team, presumably so that their immediate colleagues would work more effectively with people experiencing mental health difficulties: "pass on knowledge to colleagues" (P51). A minority of responses concerned plans to liaise with the client's friends and family: "check about social network as a priority" (P83).

\section{Qualitative Interview Findings}

Thematic analysis identified three main themes: perceived importance of training; training delivery approaches; and implications for practice (see figure 1).

Figure 1: Themes and main findings from the eight interviews

Perceived
Importance of
Training
- Non-mental health
professionals lack
knowledge and skills to
work with people
experiencing a mental
health crisis
- The training was viewed
as important
- Multi-disciplinary
training increases
understanding
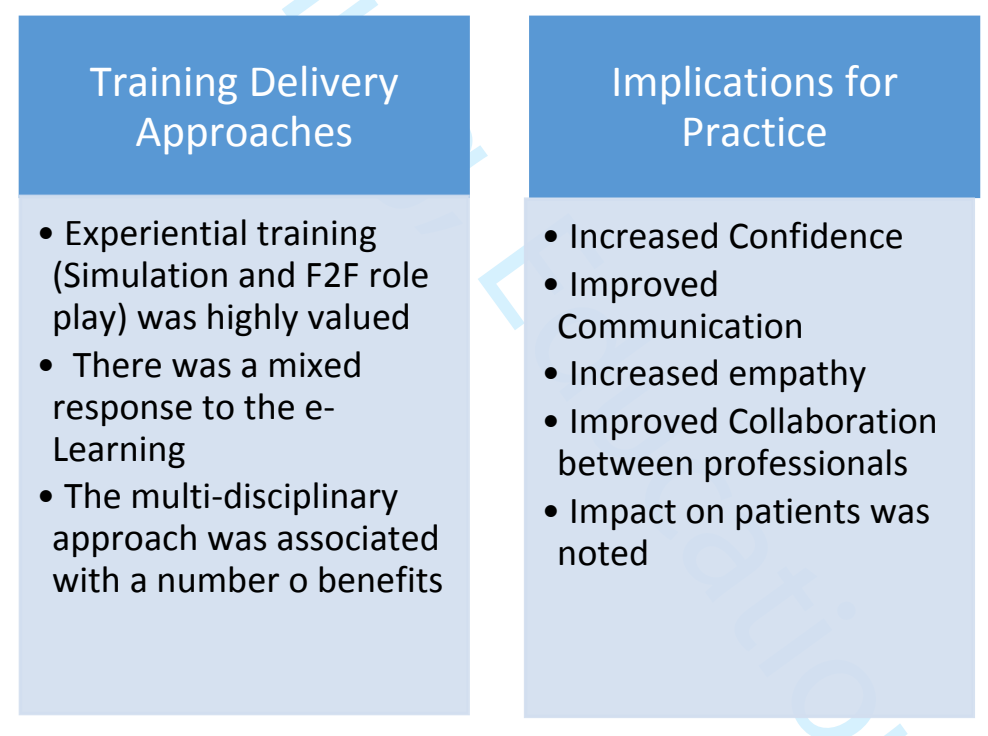

\section{Perceived Importance of Training}

Participants were consistent in agreeing that the training was important and cited several reasons for this. For instance, participants noted the current lack of training for professionals such as 
ambulance, police, and GP receptionists on managing mental health crises which they agreed meant that they lacked knowledge and understanding essential for their work.

"(We) spend hours and hours, um, with people who are threatening to...end their life, and they don't consider things like suicide impact factors, which the NHS get a lot of training in..... We don't get negotiator training, no, nothing like that...... They're relying on us to be effective communicators." (P1, police officer)

The training raised awareness among the different professionals that this lack of knowledge and understanding existed in professions other than their own, which was contrary to their expectations.

"it came to light how much...or how little knowledge or experience that they had of mental health.......they had very little understanding, and certainly had very little understanding of how...you know, the Mental Health Act is actually implemented." (P2, police officer)

"there was a lot of staff from the police there who was unaware of as regards all the mental health, erm, and...with teenagers ... teenage absconding....and what to do with the teenagers that, you know, do have problems. Erm, and what most surprised me is that I would have called the police, and they were unaware of what they should be doing." (P4, nurse)

The training was important as it equipped them with skills to use in a challenging environment where previously they had felt uncertain.

" we were taught... and it was, like, 'there's no right answer.' And, I thought that was really good, because there is no right answer, because every single situation is different, every person is different." (P8, police officer)

"I know that, even if I had a mental health practitioner with me, they would do exactly the same thing, under the circumstances. And there's no fear factor from the unknown then, which, I think a lot of my colleagues still suffer from." (P1, police officer)

\section{Training Delivery Approaches}

Some participants found the e-learning approach useful, however, others stated that there was too much. It was noted that not all participants completed the e-learning prior to attending the experiential sessions which impacted negatively on their learning. 
"I'm not a lover of e-learning... I found it quite difficult. There was, er, a lot of stuff that you had to read, ..... and I was trying to do it at work with people around me, so I found it quite, quite hard." (P8, police officer)

"the e-learning, was considerable, it was huge......(but) I thought it was important for me to do, because face to face in the education sessions, it felt like some people hadn't done it, and...they were almost at a completely different level...they didn't know what was being talked about." (P3, GP trainee)

The experiential sessions (simulation and F2F) were viewed favorably by participants. All participants, without exception, were very positive about the simulation training, which was perceived as challenging but valuable.

"They [the simulation sessions] were very stressful, but very useful. It gave us the scary crisis, high pressure situation, without it having to be a patient's life at risk...but it was useful to be able to go to pieces in a situation with an actor." (P3, GP trainee)

"There's not a lot of opportunities to practice what we're taught... we're obviously given those information about how to conduct ourselves, appropriate approaches, dealing with people... de-escalating hostile situation, but it's very rarely do we get to put that into practice in a safe controlled manner with realistic settings.....and then the feedback afterwards... it was just fantastic." (P6, police officer)

The aspect of the training consistently and strongly highlighted as valuable was the multi-disciplinary approach. It was noted that opportunities for multi-disciplinary training are rare which results in poor communication between professions who have to work together.

"joint working, sort of like as a group, was very useful..., I think it was very much an eyeopener of how little knowledge they (ambulance staff) had, you know, or how little input training they had, which.......from my point of view as a police inspector, I...kind of, they're my partners that I'm relying on as first point of call, as...as... and hoping that they would have more understanding, but it appeared not to be." (P2, police officer)

This multi-disciplinary training was valued for providing them with an understanding of others' roles and perspectives, as well as an understanding that different professions have different learning needs. 
'...for me it was working better with the paramedics for their safety and understanding their needs and what they want to get out of the situation comparatively to what [police] officers want to get out of the situation' (P6, police officer)

[MD learning was] useful because there was more than one profession represented in the room. And everyone has a different viewpoint... a different angle on how that particular issue affects their professional life...' (P1, police officer)

\title{
Implications for Practice
}

Participants consistently agreed that their knowledge of mental health and how this affects individuals and their families had increased following the training. This resulted in them having a greater empathy for people experiencing a mental health crisis, which was embedded in a more holistic view of the person than previously held.

\begin{abstract}
"it can be very frustrating.. because a lot of the time...it's not like someone's got a broken leg or cut arm. You can see the injury there, but when someone's going through a mental health problem you can't see it. So...there's a lot of patience involved and a lot of understanding and a...an appreciation for what that person's going through. And that's what's also helped .....I've got better understanding now, so I can support them better." (P6, police officer)
\end{abstract}

This increased empathy and knowledge was seen as contributing to improved confidence in interacting with people experiencing a mental health crisis. One participant noted that this had impacted positively on patient experience:

\footnotetext{
"I would like to think he was more confident because I was more confident. So, he felt calmer because I was... I was happy having him there and felt a bit more in control of what was going on, and I think that gave him confidence as well." (P7, receptionist)
}

\begin{abstract}
Participants also reported improved communication skills when working with people experiencing a mental health crisis. For instance, a nurse discussed how the training had encouraged her to check that patients would be able to follow her recommendations, rather than just giving advice and expecting them to follow it.
\end{abstract}


"It's not just, 'you must do this, and follow my advice'. I'm probably saying, 'follow my advice, do you think that's do-able?' Or, you know, 'how do you feel? Do you think you can do that? Is there anything that's stopping you?'” (P4, nurse).

And a police officer discussed how he had learned to speak to someone experiencing a psychotic episode in a more compassionate and effective way.

\begin{abstract}
"the techniques that they taught you to... how to speak to them and to obviously ask open questions... and things like, 'tell me about what's going on, I'm here to listen to you', um, kind of like showing empathy and sympathy and that.... but obviously never.....go along with what they're seeing, so if they're saying, yeah, 'there's unicorns dancing around the room and things, do you see them?', I remember the training saying never, um, encourage that kind of thing." (P5, police officer)
\end{abstract}

Participants also reported better listening skills following the training which they associated with their increased empathy for people experiencing a mental health crisis. They felt that this allowed them to ask more appropriate questions which would lead to better care delivery.

"the one thing that I took back was.... when you're dealing with somebody and, obviously, you're listening to what they're saying, but sometimes you might not always hear them because obviously your mind is sort of, racing....and....you might misinterpret what they're saying. So...so, what I found, and l've actually used this,....you reiterate back to them and you say 'so what you're saying is, the reason you're feeling low is.....' if I'd not done that then I wouldn't have maybe got to the issue that was causing them to call us." (P8, police officer).

"I think the thing that I learned from it most was about listening to people. Er, listening more and asking more questions." (P4, nurse)

\title{
Discussion
}

Non-mental health professionals from a range of urgent care settings appear to have benefited from a multi-mixed-method training to support work with people experiencing a mental health crisis. They demonstrated improved attitudes, self-efficacy in healthcare skills, confidence and knowledge relating to working with people in crisis. Qualitative analyses highlighted benefits to confidence, communication skills, empathy and multi-disciplinary collaboration. 
These findings are supported by earlier studies which demonstrate improved confidence and knowledge relating to mental healthcare following training (Fernando et al., 2017; McNaughton et al., 2008; Piette et al., 2018; Thomson et al., 2013; Zigman et al., 2013; Fernando et al., 2017; Piette et al., 2018). Similarly the low pre-training levels of mental health knowledge and confidence found here has been found in urgent care staff in other studies (Bradley, 2009; McLean and Marshall, 2010). This is concerning as these professionals support people in crisis as a significant part of their workload. Additionally, participants reported that they were not provided training opportunities and practical support for them to develop mental health specific knowledge and confidence at work. Consequently, there may have been selection bias in this study as participants self-selected to attend mental health training. Nonetheless, the low initial scores, significant increases, and reported lack of support in the workplace highlight the importance of providing such training to this staff group. A disparity is evident here between the structure of care pathways and workforce development provided, with urgent and emergency care settings and emergency services serving as the 'frontline' for many mental health crises, although little mental health training or practical support is provided in these settings.

Improved attitudes were evidenced in both the quantitative and qualitative measures useddata. This aligns to findings in the mental health training literature (McNaughton et al., 2008; Kowalski et al., 2017; Piette et al., 2018; McNaughton et al., 2008), and evidence that social contact in training interventions can reduce stigma (Mehta et al., 2015; Thornicroft et al., 2016; Mehta et al., 2015), in this case in the form of role played scenarios and simulated patients. Quantitative improvements to attitudes were contextualised by qualitative findings, highlighting increased empathy towards people in mental health crises, interest in spending more time with patients, and listening and asking questions to determine an appropriate course of action. Interview data suggested that interacting with actors (simulated patients), being able to reflect on experiences, and the opportunity to consider the perspective of patients were useful learning tools in achieving attitude change, similar to other studies (Mehta et al., 2015; Thornicroft et al., 2016; Mehta et al., 2015).-Kowalski et al., 2017; Piette et al., 2018); Thornicroft et al., 2016; Mehta al., 2015).Furthermore, interview data highlighted that participants were adopting new ways of working based on their attitude change, with reported positive effects. This suggests that training promoting attitudinal changes can be effective in improving workplace practice and behaviours.

Skill development was also demonstrated, through both improved self-efficacy scores in human factors skills, and qualitative findings. Experiential training has previously been found beneficial for this (Billon et al., 2016; Kowalski et al., 2017; Lavelle et al., 2017). The most notable skills highlighted 
were communication and multidisciplinary collaboration, which are essential for the delivery of high quality, safe patient care (Leonard et al, 2004). These elements were attributed to the opportunity to practice and learn from others, as well as engage in interprofessional education with a multidisciplinary group of participants. This is an important finding to note for those developing nonmental health workforces to support people with mental health needs: emphasising the importance of effective communication, understanding others' roles and skills and how these relate to providing appropriate care appears key. While obtaining interprofessional and multidisciplinary groups for training in mental health can be challenging, this data suggests that doing so is particularly beneficial.

\section{Limitations}

Findings from across datasets are consistent which implies that findings are valid. However, a larger sample for the qualitative study would have ensured that each professional group was adequately represented and that all aspects of the training had been discussed. Nevertheless, despite having different backgrounds and experience, participants' views were consistent. While the findings from interviews were useful in highlighting the longitudinal impact of the training, this requires replication on a larger scale to determine effectiveness.

Validated outcome measures were used where possible, but a lack of appropriate evaluation tools meant that some tools were created for this study. Nonetheless, this study has a large sample for an educational intervention study in this field, with sufficient quantitative data to draw robust findings However, there were insufficient participants to determine whether there were perceived differences in experience and benefits gained according to which training methods have been accessed, with only interview data able to address this question. Additionally, data collection was entirely based on self-report, raising the possibility of data being influenced by biases, including social desirability. Likewise, a lack of control group comparisons prevents interpretation of the specific effects and learning that have originated from the training sessions.

Finally, this evaluation could not fully assess the impact of the training on professional practice or on patient experience. Questionnaire data and free-text comments suggest that staff intended to implement the new knowledge and skills they had developed, and interview data, including where staff had provided specific examples, indicate that staff had changed their practice. However, further research including objective measurement of clinical practice, outcomes and experience would be merited to determine changes in practice. 


\section{Conclusions}

Mental health crisis training for non-mental health professionals can improve confidence, knowledge, healthcare skills, attitudes and potentially the clinical practice of staff who work in urgent care settings. Investment in such training provision and in research that clarifies the impact on clinical practice and patient experience in a highly important part of the healthcare delivery system is merited.

\section{Acknowledgements}

This study was funded by Health Education England Thames Valley. The funder specified what training was required, but the evaluation was conducted independently by the research team.

\section{References}

Attoe, C., Kowalski, C., Fernando, A., and Cross, S. (2016), "Integrating mental health simulation into routine health-care education", The Lancet Psychiatry, Vol. 3 No. 8, pp.702-703.

Billon, G., Attoe, C., Marshall-Tate, K., Riches, S, Wheildon, J. and Cross S. (2016), "Simulation training to support healthcare professionals to me.et the health needs of people with intellectual disabilities", Advances in Mental Health and Intellectual Disabilities, Vol. 10 No. 5, pp.284-292.

Blumenthal, D. M., Bernard, K., Fraser, T. N., Bohnen, J., Zeidman, J. and Stone, V. E. (2014), "Implementing a pilot leadership course for internal medicine residents: Design considerations, participant impressions, and lessons learned", BMC Medical Education, 14: 57.

Bradley, K. J. C. B. (2009), "The Bradley Report: Lord Bradley's review of people with mental health problems or learning disabilities in the criminal justice system", Department of Health, London.

Bremner, M. N., Aduddell, K., Bennett, D. N., VanGesst, J. B. (2006), "The Use of Human Patient Simulators Best Practices With Novice Nursing Students", Nurse Educator, Vol. 31 No. 4, pp.170-174.

Care Quality Commission (CQC) (2015) "Right here, right now: Mental health crisis care review" available from: http://www.cqc.org.uk/content/right-here-right-now-mental-health-crisis-carereview. 
Clifton, A., Burgess, C., Clement, S., Ohlsen, R., Ramluggun, P., Sturt, J., Walters, P. and Barley, E.A. (2016), "Influences on uptake of cancer screening in mental health service users: a qualitative study", BMC Health Services Research, 16:257. doi: 10.1186/s12913-016-1505-4

Dorri, S., Akbari, M., and Dorri Sedeh, M. (2016), "Kirkpatrick evaluation model for in-service training on cardiopulmonary resuscitation", Iranian Journal of Nursing and Midwifery Research, Vol. 21 No. 5 pp.493-497. doi:10.4103/1735-9066.193396.

Evans-Lacko, S., Rose, D., Little, K., Flach, C., Rhydderch, D., Henderson, C., Thornicroft, G. (2011), "Development and psychometric properties of the Reported and Intended Behaviour Scale (RIBS): a stigma-related behaviour measure", Epidemiology and Psychiatric Sciences, Vol. 20 No. 3, pp.263271.

Fernandez, C. S. P., Noble, C. C., Jensen, E. and Steffen, D. (2015), “Moving the needle: A retrospective pre- and post-analysis of improving perceived abilities across 20 leadership skills", Maternal and Child Health Journal, Vol. 19, pp. 343-352.

Fernando, A., Attoe, C., Jaye, P., Cross, S., Pathan, J., and Wessely, S. (2017), “Improving interprofessional approaches to physical and psychiatric comorbidities through simulation", Clinical Simulation in Nursing, Vol. 13, pp. 186-193. doi:10.1016/j.ecns.2016.12.004

Fisher, M., Vishwas, A., Cross, S., and Attoe, C. (2019), "Simulation training for Police and Ambulance Services: improving care for people with mental health needs", BMJ Simulation and Technology Enhanced Learning, Vol. 1, pp.1-2.

Gabbidon, J., Clement, S., Van Nieuwenhuizen, A., Kassam, A., Brohan, E., Norman, I., Thornicroft, G. (2013), "Mental Illness: Clinicians' Attitudes (MICA) Scale-Psychometric properties of a version for healthcare students and professionals", Psychiatry Research, Vol. 206 No. 1, pp.81-87.

Goldfarb, E., and Gorrindo, T. (2013), "Simulation in psychiatry", in Levine, A. I., DeMaria Jr., S., Schwartz, A. D., Sim, A. J. (Eds.), The Comprehensive Textbook of Healthcare Simulation, Springer, New York, NY. pp. 511-523.

Green, J., and Thorogood, N. (2004), Qualitative methods for Health Research. Sage Publications Ltd, London. 
IBM Corp. Released 2012. IBM SPSS Statistics for Windows, Version 21.0. Armonk, NY: IBM Corp.

Kirkpatrick, D. L. (1959), "Techniques for evaluating training programs", Journal of American Society Directors, Vol.1, pp.3-9.

Kirkpatrick, D. L. (1998), Evaluating training programs: The four levels, 2nd ed. Berrett-Koehler Publishers, California.

Kowalski, C., Attoe, C., Ekdawi, I., Parry, C., Phillips, S., and Cross, S. (2017), "Interprofessional simulation training to promote working with families and networks in mental health services", Academic Psychiatry, Vol. 42 No. 5 pp.605-612.

Lavelle, M., Attoe, C., Tritschler, C., and Cross, S. (2017), "Managing medical emergencies in mental health settings using an interprofessional in-situ simulation trianing programme: A mixed methods evaluation study", Nurse Education Today, Vol.59, pp.103-109. doi:10.1016/j.nedt.2017.09.009

Lavoie-Tremblay, M., Anderson, M., Bonneville-Roussy, A., Drevniok, U. and Lavigne, G. L. (2012), "Nurse executives' perceptions of the Executive Training for Research Application (EXTRA) program", Worldviews on Evidence-Based Nursing, Vol. 9, pp.186-192.

Leonard, M., Graham, S., and Bonacum, D. (2004), "The human factor: the critical importance of effective teamwork and communication in providing safe care", BMJ Quality \& Safety, Vol. 13 Supplement 1, pp.i85-i90.

Mclean, N., and Marshall, L. A. (2010), "A front line police perspective of mental health issues and services", Criminal behaviour and mental health, Vol. 20 No. 1, pp. 62-71.

McNaughton, N., Ravitz, P., Wadell, A., and Hodges, B. D. (2008), "Psychiatric education and simulation: a review of the literature", The Canadian Journal of Psychiatry, Vol. 53 No. 2, pp. 85-93.

Mehta, N., Clement, S., Marcus, E., Stona, A-C., Bezborodovs, N., Evans-Lacko, S., Palacios, J., Doherty, M., Barley, E., Rose, D., Koschorke, M., Shidhazye, R., Henderson, C. and Thornicroft, G. (2015), “Evidence for effective interventions to reduce mental Health-related stigma and discrimination in the medium and long term: Systematic review", British Journal of Psychiatry, Vol. 207 No. 5, pp.377-84 
Mental Health Crisis Care Concordat (2014), "Improving outcomes for people experiencing mental health crisis", Department of Health, London https://www.gov.uk/government/publications/mentalhealth-crisis-care-agreement

Miller, D., Crandall, C., Washington III, C., and McLaughlin, S. (2012), "Improving teamwork and communication in trauma care through in situ simulations", Academic Emergency Medicine, Vol. 19 No. 5, pp. 608-612.

O'Reilly, C. L., Bell, J. S., and Chen, T. F. (2010), “Consumer-led mental health education for pharmacy students", American Journal of Pharmaceutical Education, Vol. 74 No. 9, Article. 167.

Piette, A. E., Attoe, C., Humphreys, R., Cross, S,. and Kowalski, C. (2018) “Interprofessional simulation training for community mental health teams: Findings from a mixed methods study", Journal of Interprofessional Care, Vol. 32 No. 6, pp. 762-770.

Reedy, G. B., Lavelle, M., Simpson, T., \& Anderson, J. E. (2017). Development of the Human Factors Skills for Healthcare Instrument: a valid and reliable tool for assessing interprofessional learning across healthcare practice settings. BMJ Simulation and Technology Enhanced Learning, Vol. 3 No. 4, pp.135-141.

Rong, Y., Glozier, N., Luscombe, G. M., Davenport. T. A., Huang, Y., and Hickie, I. B. (2011), "Improving knowledge and attitudes towards depression: a controlled trial among Chinese medical students", BMC Psychiatry, 11: 36.

Scantlebury, A., Fairhurst, C., Booth, A., McDaid, C., Moran, N., Parker, A. and Hewitt, C. (2017), "Effectiveness of a training program for police officers who come into contact with people with mental health problems: A pragmatic randomised controlled trial", PloS one, 12(9), e0184377.

Thomson, A. B., Cross, S., Key, S., Jaye, P., and Iversen, A. C. (2013), “How we developed an emergency psychiatry training course for new residents using principles of high-fidelity simulation", Medical teacher, Vol. 35 No. 10, pp. 797-800. 
Thornicroft, G., Mehta, N., Clement, S., Evans-Lacko, S., Doherty, M., Rose, D., Koschorke, M., Shidhaye, R., O'Reilly, C. and Henderson, C. (2016), "Evidence for effective interventions to reduce mental-health-related stigma and discrimination”, The Lancet, Vol. 387 No. 10023, pp. 1123-1132.

Zigman, D., Young, M., and Chalk, C. (2013), “Using simulation to train junior psychiatry residents to work with agitated patients: a pilot study", Academic Psychiatry, Vol. 37 No. 1, pp. 38-41. 